\title{
High Sensitivity C - Reactive Protein is Associated with Diastolic Dysfunction in Young African Americans without Clinically Evident Cardiac Disease
}

\author{
Venkataraman Rajaram ${ }^{1}$, Arthur T. Evans ${ }^{2}$, Gloria C. Caldito ${ }^{3}$, Russell F. Kelly ${ }^{4}$, Leon Fogelfeld ${ }^{5}$, \\ Henry R. Black ${ }^{6}$ and Rami Doukky ${ }^{7, *}$
}

${ }^{I}$ Section of Cardiology, Temple University Health Sciences Center, Philadelphia, PA, USA

${ }^{2}$ Department of Medicine, John H Stroger, Jr. Hospital of Cook County, Chicago, IL, USA

${ }^{3}$ Department of Biometry, Louisiana State University Health Sciences Center, Shreveport, LA, USA

${ }^{4}$ Division of Cardiology, John H Stroger, Jr. Hospital of Cook County, Chicago, IL, USA

${ }^{5}$ Division of Endocrinology, John H Stroger, Jr. Hospital of Cook County, Chicago, IL, USA

${ }^{6}$ Center for the Prevention of Cardiovascular Disease, New York University, New York, NY, USA

${ }^{7}$ Section of Cardiology, Rush University Medical Center and John H Stroger, Jr. Hospital of Cook County, Chicago, IL, USA

\begin{abstract}
Background: Diastolic dysfunction (DD) is associated with myocardial fibrosis mediated by inflammation. Higher levels of inflammation found in African Americans (AAs) may predict DD among asymptomatic individuals. We tested the hypothesis that high sensitivity C-reactive protein (hs-CRP), a biomarker of inflammation, is associated with DD in asymptomatic AAs.

Methods: We prospectively recruited 107 asymptomatic AAs without any history of cardiac, renal or inflammatory diseases or alcoholism. We measured hs-CRP and B-type Natriuretic peptide (BNP) levels and estimated left ventricular end diastolic pressure (LVEDP), mass and systolic function with echocardiography. Multivariate logistic regression analysis was used to define whether hs-CRP is an independent predictor of LVEDP.

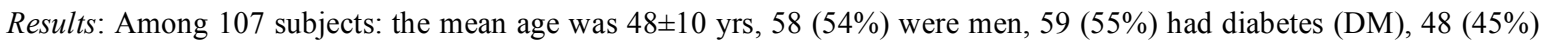
had hypertension $(\mathrm{HTN})$, the mean BMI was $30.5 \pm 4.8$ and the mean ejection fraction was $63.1 \pm 5.8 \%$. DD was present in 56(52\%) subjects, 38 (36\%) of whom also had a high LVEDP. On multivariate analysis, hs-CRP was independently associated with DD [odds ratio $3.36(95 \% \mathrm{CI}=1.07-10.5, \mathrm{p}=0.04$ ]. There was a $61 \%$ and $133 \%$ increase in the prevalence of any DD and DD with high LVEDP, respectively, between the lowest and the highest hs-CRP quartiles.

Conclusion: Diastolic dysfunction is prevalent among asymptomatic African Americans and it is independently associated with elevated level of hs-CRP, an inflammation marker.
\end{abstract}

Keywords: Diastolic dysfunction, Inflammation, High sensitivity C-reactive protein, Biomarkers.

\section{INTRODUCTION}

Diastolic dysfunction (DD) is the predominant pathophysiological mechanism in a third of the heart failure population [1-6]. Inflammatory fibrosis of the myocardium is thought to be a major cause of myocardial stiffening leading to the development of $\mathrm{DD}$. The higher prevalence of proinflammatory conditions such as diabetes (DM) and hypertension (HTN) and the higher levels of inflammatory markers often found in African Americans (AA) may predispose them to myocardial stiffening and $\mathrm{DD}$, ultimately resulting in symptomatic heart failure [7-11]. We conducted this cross

*Address correspondence to this author at the Rush University Medical Center, Section of Cardiology, Jelke \# 1015d Chicago, IL 60612, USA;

Tel: 312-563-2534; Fax: 312-942-6334;

E-mail:rami_doukky@rush.edu sectional study to test the hypothesis that high sensitivity C-reactive protein (hs-CRP), a biomarker of inflammation, is associated with DD and is a clinical predictor of incipient diastolic heart failure in asymptomatic AA subjects.

\section{METHODS}

\section{Study Subjects}

We prospectively screened 135 AAs between the ages of 20 and 65 years with no known history of heart disease or cardiovascular symptoms who visited an outpatient walk-in clinic between March 2004 and May 2006 at an urban healthcare center in Chicago. Of those 117 were included in the study (18 declined to participate) (Fig. 1). They presented to the clinic for medications for their underlying chronic conditions or for unrelated medical problems. A 


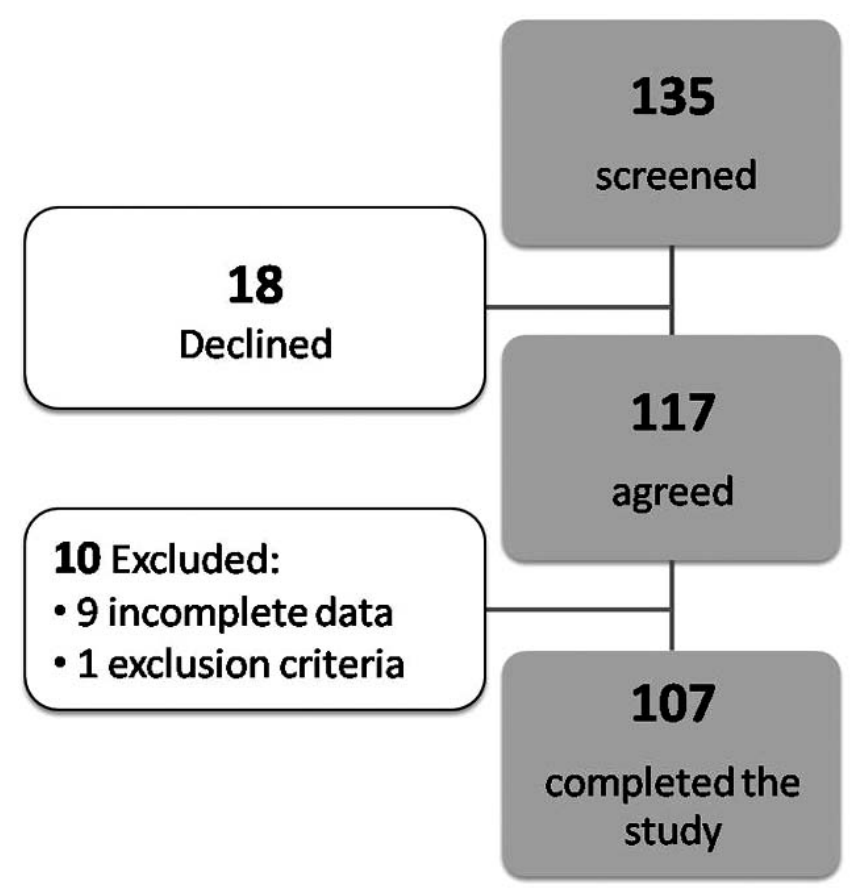

Fig. (1). Study Scheme DD - diastolic dysfunction, DM - diabetes mellitus, hs-CRP = high sensitivity C-reactive, HTN - hypertension, LVEDP $=$ left ventricular end diastolic pressure.

standardized interview and physical exam was administered to all subjects. Blood pressure was measured using established methods [12]. HTN was defined as a systolic blood pressure $\geq 140 \mathrm{~mm} \mathrm{Hg}$ and/or a diastolic blood pressure $\geq 90$ $\mathrm{mm} \mathrm{Hg}$ or receiving antihypertensive drug therapy [13]. Subjects were classified as having DM if they had a history of type 2 diabetes diagnosed with the American Diabetic Association criteria or were on medications for diabetes [14]. We successfully recruited approximately equal number of subjects who had HTN and DM, DM only, HTN only and neither HTN nor DM as planned.

Subjects were excluded if they had signs and symptoms of heart failure or other cardiac symptoms, history of prior cardiovascular diseases (myocardial infarction, coronary artery disease, heart failure, valvular heart disease, arrhythmia, bundle branch block, wall motion abnormalities on earlier echo, stroke, and peripheral vascular disease), newly diagnosed (less than one year) DM or HTN or type 1 DM, serum creatinine $\geq 1.6 \mathrm{mg} / \mathrm{dl}$, history of cocaine or heroin use in the last 6 months, alcoholism (defined as at least two positive responses to CAGE questionnaire), [15] body mass index $(\mathrm{BMI}) \leq 18.5$ or $\geq 40$ and conditions associated with acute hs-CRP elevation (those with signs of acute systemic infection/inflammation such as fever or the use of estrogens in any form) [16-19].

Laboratory measurements included serum creatinine levels, hemoglobin $\mathrm{A}_{1} \mathrm{C}\left(\mathrm{HbA}_{1} \mathrm{c}\right)$, b-type natriuretic peptide (BNP) (Advia Centaur Immunoassay systems, Bayer diagnostics, New York, USA) and hs-CRP levels (Immulite 2000 immunometric assay, DPC, California, USA). Any value below the lowest possible measurement of BNP $(<0.5 \mathrm{pg} / \mathrm{dl})$ and hs-CRP value $(<0.02 \mathrm{mg} / \mathrm{dl})$ was considered zero. All subjects provided written informed consent. The Scientific Research Committee of the hospital approved this study. This human investigation conforms to the principles outlined in the Declaration of Helsinki.

\section{Echocardiography}

M-mode, 2D, Doppler and tissue Doppler imaging was performed on all subjects using standard techniques. Ejection fraction and wall motion abnormalities were assessed visually. Measurements of interventricular septal thickness (IVST), posterior wall thickness (PWT) and left ventricular internal diameter (LVID) were made at end-diastole and endsystole according to the American Society of Echocardiography (ASE) recommendations [20]. Left ventricular (LV) mass was calculated using the ASE formula with Devereux's correction and raised to the power 2.7 (LV mass indexLVMI) to minimize the errors in estimating the impact of overweight $[21,22]$.

All participants had a pulsed-wave Doppler examination of mitral inflow and of pulmonary venous inflow. Doppler velocities of early (E) and late diastolic mitral flow (A), the deceleration time (DT) and the $\mathrm{E} / \mathrm{A}$ ratio (including $\Delta \mathrm{E} / \mathrm{A}$ ratio with Valsalva maneuver) were measured. Pulmonary venous peak systolic flow velocity and diastolic flow velocity were also obtained [23]. Tissue Doppler imaging was obtained at the medial mitral annulus. The early $\left(\mathrm{e}^{\prime}\right)$ and late diastolic velocities (a') were determined and the ratio of the transmitral flow velocity and annular velocity (E/e') was performed to assess LV end diastolic pressure (LVEDP). The prediction of elevated filling pressure was primarily based on $\mathrm{E} / \mathrm{e}$ ' ratio $>10$ and a decrease in $\mathrm{E} / \mathrm{A}$ ratio by 0.5 with Valsalva maneuver [24]. Subjects with E/e' $\leq 10$ were considered to have normal LVEDP [25-27].

\section{Classification of Diastolic Dysfunction}

Using standard criteria for Doppler measurements of mitral inflow, pulmonary venous flow and tissue velocities, diastolic function was categorized into normal, DD with normal LVEDP (DD1) (impaired relaxation, also known as grade-1 DD) and DD with high LVEDP (DD2). The latter group includes subjects with impaired relation with elevated LVEDP (also known as grade-1B), pseudonormal filling pattern (grade-2 DD) and advanced DD (grade 3, restrictive filling pattern) $[3,23]$. LVEDP and diastolic function classification were adjudicated by a cardiologist who is an expert in echocardiographic assessment of diastolic function. Rules utilized in predicting LVEDP and diastolic function classification are consistent with the subsequently published recommendations of American Society of Echocardiography [28].

\section{Statistical Analysis}

Association of $\mathrm{DD} 1, \mathrm{DD} 2$ or $\mathrm{E} / \mathrm{e}^{\prime}$ ratio with hs-CRP was determined controlling for the effects of possible confounders (age, sex, diabetes, hypertension, BMI and LVM index) and that of BNP. Separate logistic regression analyses were used to determine association of DD1 or DD2 with hs-CRP, BNP, age, sex, BMI, LVM index, DM, or HTN unadjusted for any other factor. Multiple logistic regression analysis was used to determine association of 
DD1 or DD2 with hs-CRP controlling for the effects of significant confounders and BNP. The assumptions and validity of the logistic regression model was ascertained (model fitting information, goodness of fit). Spearman rank correlation was used to determine unadjusted correlation between E/e' ratio and hs-CRP while the Wilcoxon rank sum test was used to determine association of $\mathrm{E} / \mathrm{e}^{\prime}$ ratio with sex, DM and HTN by comparing average value of E/e' ratio between categories of these possible confounders. The general linear model was used to determine significant association between E/e' ratio and hs-CRP adjusted for the effects of significant confounders and BNP. The quartiles for hs-CRP were compared for prevalence of (DD1) and (DD2) using the chi-square test.

\section{RESULTS}

In all, of 117 subjects recruited, 107 completed the study procedures ( 9 had incomplete data and 1 met exclusion criteria, Fig. 1). The baseline characteristics are presented in Table 1. Echocardiogram revealed any DD in $56(52 \%)$ of these asymptomatic individuals: 18 (17\%) had mild DD (DD1) with normal LVEDP (E/e' ratio $\leq 10)$ and $38(36 \%)$ had DD with elevated LVEDP (DD2) $\left[\mathrm{E} / \mathrm{e}^{\prime}\right.$ ratio $>10$ and a decrease in $\mathrm{E} / \mathrm{A}$ ratio by 0.5 with Valsalva maneuver].

Table 1. Baseline Characteristics

\begin{tabular}{|c|c|}
\hline Characteristics & Participants $(n=107)$ \\
\hline Age $(\mathrm{yrs})($ mean \pm SD) & $48 \pm 10$ \\
\hline Men & $58(54 \%)$ \\
\hline Diabetic not hypertensive & $32(30 \%)$ \\
\hline Hypertensive not diabetic & $21(20 \%)$ \\
\hline Diabetic hypertensive & $27(25 \%)$ \\
\hline Not diabetic not hypertensive & $27(25 \%)$ \\
\hline Body mass index $(\mathrm{kg} / \mathrm{m} 2)($ mean $\pm \mathrm{SD})$ & $30.5 \pm 4.8$ \\
\hline Systolic blood pressure $(\mathrm{mm} \mathrm{Hg})($ mean $\pm \mathrm{SD})$ & $124 \pm 17$ \\
\hline Diastolic blood pressure $(\mathrm{mm} \mathrm{Hg})($ mean $\pm \mathrm{SD})$ & $78 \pm 11$ \\
\hline Glycosylated hemoglobin HbAlc $(\%)($ mean \pm SD) & $7.9 \pm 2.5$ \\
\hline hs-CRP levels (mg/dl) (mean) (range) & $0.5(0.02-4.65)$ \\
\hline hs-CRP levels $(\mathrm{mg} / \mathrm{dl})\left(<25^{\text {th }}\right.$ percentile $)$ & $\leq 0.1$ \\
\hline hs-CRP levels (mg/dl) $\left(25^{\text {th }}-75^{\text {th }}\right.$ percentile $)$ & $0.11-0.61$ \\
\hline hs-CRP levels ( $\mathrm{mg} / \mathrm{dl})\left(>75^{\text {th }}\right.$ percentile $)$ & $\geq 0.614$ \\
\hline BNP levels (pg/dl) & $18.7(0-180)$ \\
\hline LV mass (gm) & $158 \pm 49$ \\
\hline $\operatorname{LVMI}\left(\mathrm{gm} / \mathrm{m}^{2.7}\right)$ & $38 \pm 11.4$ \\
\hline Ejection fraction (mean $\pm \mathrm{SD}$ ) & $63.1 \pm 5.8 \%$ \\
\hline
\end{tabular}

$\mathrm{BNP}=$ b-type natriuretic peptide, hs-CRP $=$ high sensitivity $\mathrm{C}$-reactive protein, $\mathrm{LV}=$ left ventricle, LVMI = left ventricular mass index.
Univariate analyses of various factors associated with DD1 and DD2 were made and the results are shown in Table 2. Age, BMI, HTN and LVMI were significant confounding factors for the association between hs-CRP and DD2 and $\mathrm{E} / \mathrm{e}^{\prime}$ ratio. These same factors except $\mathrm{BMI}$ were the significant confounding factors for the association between hs-CRP and DD1. There was no significant association between BNP and DD1 $(p=0.66)$, DD2 $(p=0.16)$ or $E / e^{\prime}$ ratio $(p=0.61)$ and hence were not included in the multivariate analysis.

Table 3 shows significant association between hs-CRP and DD1 $(p=0.04)$, DD2 $(p=0.02)$, and $E / e^{\prime}$ ratio $(p=0.006)$ adjusted for the effects of confounding factors in the multivariate analysis. For every unit increase in hs-CRP, there were significant increases of $3.36 \%$ and $3.62 \%$ in odds for DD1 and DD2, respectively, adjusted for the effect of confounding factors. There was a significant contribution of hs$\mathrm{CRP}$ to the observed variability of $\mathrm{E} / \mathrm{e}^{\prime}$ ratio ( $\mathrm{F}$ ratio of mean square for hs-CRP to mean square for error=7.93) controlling for the effects of confounding factors. Independent risk factors for DD2 and E/e' ratio were age, LVM index and hsCRP whereas only age and hs-CRP were the independent risk factors for DD1.

There was an overall significant difference in overall all prevalence of any DD $(p=0.03)$ and DD2 $(p=0.003)$ rates among the hs-CRP quartile groups. There were significant pair wise differences among the hs-CRP groups 1 and 3 $(p=0.008)$ and between groups 2 and $3(0.001)$ in rate of occurrence of DD (Fig. 2).

Of all the participants 3 were found to have mild upper respiratory infection with no fever or systemic symptoms. Exclusion of these participants from the analysis did not change the outcome.

\section{DISCUSSION}

Myocardial stiffness and DD can result from cardiac fibrosis caused by the increased deposition of collagen in the interstitium mediated in part by inflammatory processes $[1,29,30]$. Small studies have suggested that low-grade systemic inflammation is associated with high arterial stiffness, which in turn is associated with the stiffening of the ventricle and diastolic heart failure [31-34]. African American subjects have a higher prevalence of proinflammatory conditions like DM and HTN, which puts them at a risk of an earlier onset and accelerated progression of arterial stiffness and are at high risk for diastolic dysfunction [35].

In the present study of asymptomatic AA subjects, the prevalence of DD including those with high LVEDP was very high $(56 \%)$. DD to this degree in a relatively young population may be of considerable clinical importance, since the presence of DD is a powerful predictor of symptomatic heart failure and all-cause mortality $[3,36]$. The most important finding of the present study is the strong association between DD and elevated hs-CRP levels, independent of DM, HTN, BMI, and LV hypertrophy. It is also important to note that those with higher hs-CRP levels tend to have more advanced DD with elevated LVEDP. Others have reported an association between hs-CRP levels and LVEDP in patients with heart failure [37]. Our data suggests that this association appears to exist even in those with asymptomatic 
Table 2. Factors Associated with Diastolic Dysfunction by Univariate Analysis

\begin{tabular}{|c|c|c|}
\hline \multirow[t]{3}{*}{ DD1 } & Age: $\mathrm{OR}=1.19$ (1.11 to 1.27$)$ & $<0.01$ \\
\hline & LVM Index: $\mathrm{OR}=1.07$ (1.03 to 1.12$)$ & $<0.01$ \\
\hline & Hs-CRP: OR=3.94 (1.32 to 11.72$)$ & 0.014 \\
\hline \multirow{4}{*}{ DD2 } & HTN: $\mathrm{OR}=5.56(2.38$ to 12.50$)$ & $<0.01$ \\
\hline & BMI: $\mathrm{OR}=1.11(1.02$ to 1.21$)$ & 0.02 \\
\hline & LVM Index: OR=1.09 (1.04 to 1.14$)$ & $<0.01$ \\
\hline & Hs-CRP: $\mathrm{OR}=4.35$ (1.61 to 11.77$)$ & $<0.01$ \\
\hline \multirow{3}{*}{ E/e' } & BMI: Spearman rank correlation coefficient $=0.234$ & 0.02 \\
\hline & Hs-CRP: Spearman rank correlation coefficient $=0.340$ & $<0.01$ \\
\hline & HTN: $10.8 \pm 3.3$ (Yes) vs. $8.3 \pm 2.9$ (No) [comparison of means] & $<0.01$ \\
\hline
\end{tabular}

$\mathrm{BMI}=$ body mass index, Hs-CRP $=$ high sensitivity C-reactive protein, $\mathrm{HTN}=$ hypertension, $\mathrm{LVMI}=$ left ventricular mass index, $\mathrm{DD}=$ diastolic dysfunction .

Table 3. Factors Associated with Diastolic Dysfunction after Adjusting for the Effect of Confounders

\begin{tabular}{|c|c|c|}
\hline \multirow[t]{3}{*}{ DD1 } & hs-CRP: $O R=3.36(1.07$ to 10.52$)$ & $0.04 *$ \\
\hline & LVM: OR=1.04 (0.99 to 1.10$)$ & $0.15^{\mathrm{NS}}$ \\
\hline & HTN: $O R=2.17(0.72$ to 6.25$)$ & $0.17^{\mathrm{NS}}$ \\
\hline \multirow{3}{*}{ DD2 } & Age: $\mathrm{OR}=1.10(1.03$ to 1.17$)$ & $0.006 * *$ \\
\hline & LVM: OR=1.07 (1.01 to 1.13$)$ & $0.02 *$ \\
\hline & HTN: OR=1.65 (0.55 to 5.00$)$ & $0.36^{\mathrm{NS}}$ \\
\hline \multirow{3}{*}{ DD3 } & LVM: $\mathrm{MS}=45.76, \mathrm{~F}=5.92$ & $0.02 *$ \\
\hline & HTN: $\mathrm{MS}=7.97, \mathrm{~F}=1.03$ & $0.31^{\mathrm{NS}}$ \\
\hline & BMI: $\mathrm{MS}=.04, \mathrm{~F}=.01$ & $0.94^{\mathrm{NS}}$ \\
\hline
\end{tabular}

**Significant at $1 \%$ level of significance (p-value $<0.01)$, ${ }^{*}$ Significant at $5 \%$ level of significance $(0.01<\mathrm{p}$-value $<0.05)$, ${ }^{\mathrm{NS}}$ Not Significant at $5 \%$ level of significance (p-value $>0.05$ ), ${ }^{1} \mathrm{MS}-$ Mean Square for factor in general linear regression model, ${ }^{2} \mathrm{~F}-$ Ratio of MS (factor) to mean square error for testing significant effect of factor on E/e' ratio BMI $=$ body mass index, Hs-CRP = high sensitivity C-reactive protein, $\mathrm{HTN}=$ hypertension, LVMI = left ventricular mass index, $\mathrm{DD}=$ diastolic dysfunction

DD. The strong independent association between hs-CRP levels, a well-established marker of inflammation and DD may indicate that inflammation plays a prominent role in the development of DD. It was also interesting to note that the
BNP levels were not significantly associated with DD in this asymptomatic population. It has been noted by others as well that in asymptomatic population with diastolic dysfunction BNP may not always be elevated [38, 39]. 


\section{Diastolic Dysfunction (DD2 and any DD) by hs-CRP Quartile Groups}

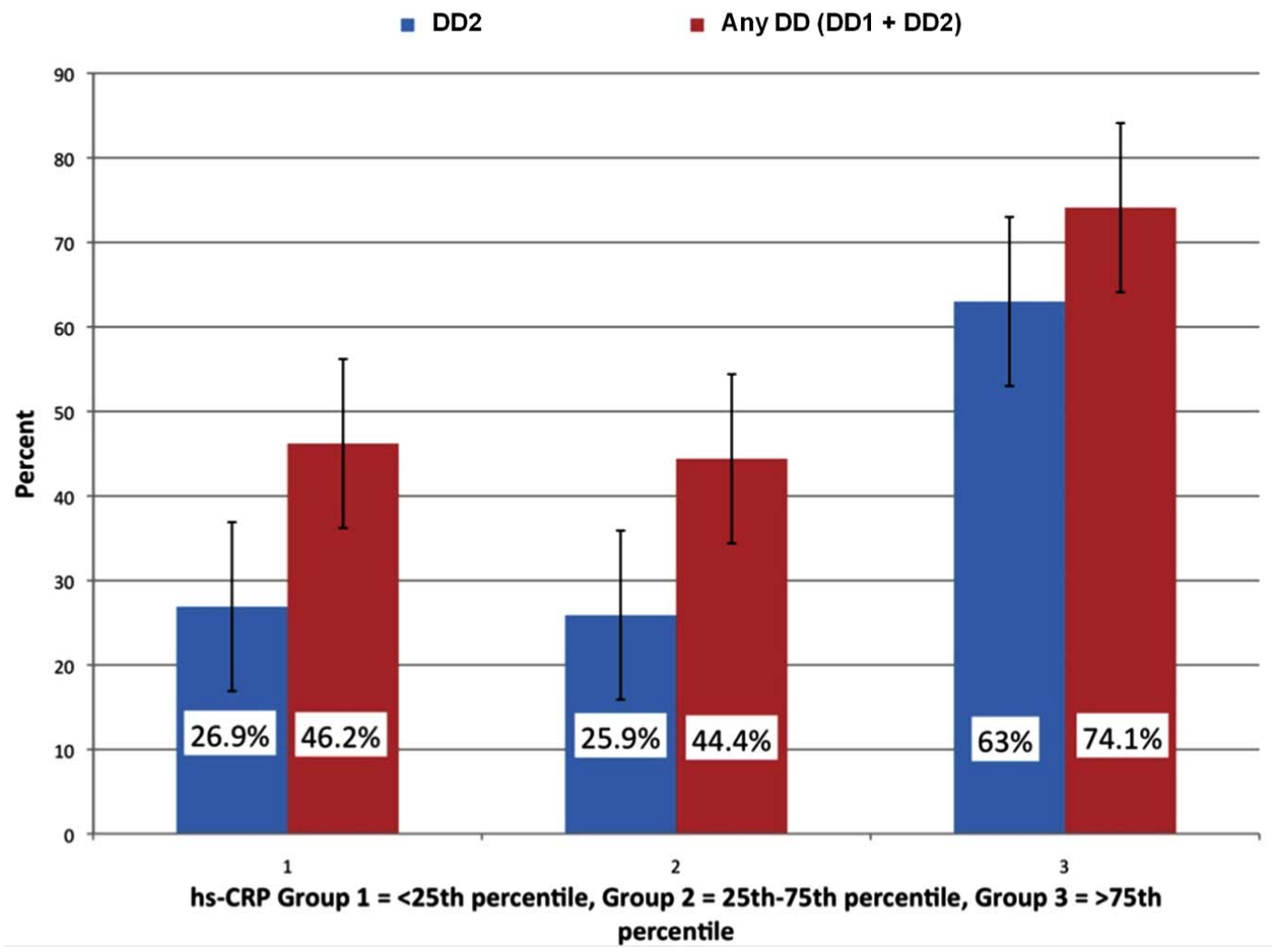

Fig. (2). Rates of DD by hs-CRP quartiles. Overall DD and DD2 rates were significantly different among the hs-CRP quartile groups ( $\mathrm{p}=0.03$ and $\mathrm{p}=0.003$ respectively). There were significant pair wise differences among the hs-CRP quartile groups 1 and 3 ( $\mathrm{p}=0.008)$ and groups 2 and $3(0.001)$ in the rate of occurrence of any DD.

We conclude that hs-CRP appeared to be an important clinical predictor of DD in this cohort independent of the other clinical predictors of DD like age, HTN, DM and BNP. Therefore, it may be another potential biomarker of incipient heart failure.

\section{Mechanism of Association between Inflammation and DD}

Myocardial fibrosis in diastolic heart failure is characterized by poorly structured and fractured collagen in the extracellular matrix (ECM) [10, 29, 40, 41]. Matrix metalloproteinases (MMP) are enzymes released by macrophages and fibroblasts, which modulate the remodeling of the ECM [41, 42]. These MMPs and the tissue inhibitors of matrix metalloproteinases (TIMPs) are in turn regulated by inflammatory cytokines such as C-reactive protein $[41,43,44]$.

Further support to the etiological role of inflammation in causing DD comes from animal studies where normalization of DD was achieved using anti-inflammatory agents independent of the resolution of LV hypertrophy $[45,46]$. Inflammation has been proposed to be a common pathway through which conditions like HTN and DM lead to ventricular stiffness and DD and eventually to decompensated heart failure.

Alternatively it can be speculated based on current body of evidence that elevated hs-CRP may be either a marker or mediator of impaired coronary blood flow reserve which is known to be associated with ventricular fibrosis and diastolic dysfunction [47-49].

With the increase in DM, HTN and obesity, the prevalence of DD is likely to increase in the near future. To date, the management of DD in clinical practice is based mostly on our knowledge of the pathophysiology and trial data in established diastolic heart failure [50]. There are few specific interventions to reverse DD and to prevent the development of symptomatic heart failure once DD is detected. If the association between inflammation and DD can be confirmed by further study in humans, controlling inflammation could be a target for therapy for DD and possibly for the prevention of symptomatic heart failure [51]. The hs-CRP level also has the potential to be useful in identifying those at risk for DD and possibly predict those who are likely to progress to symptomatic heart failure, pending confirmation by prospective and long-term observational studies.

\section{STUDY LIMITATIONS}

We recruited patients for this study from an outpatient walk-in clinic of an inner-city hospital. Many patients visit this facility to obtain medication refills for their underlying chronic condition. This may explain the high proportion of patients with type-2 DM, as these individuals may have disproportionately frequented the clinic for the sole purpose of obtaining a medication refill. Additionally, this fact would suggest that patients recruited may have been sub-optimally 
managed for their underlying chronic condition as they utilized an urgent care center rather than a steady primary care physician to treat these conditions. Possibly, we may have included patients who ran out of their antihypertensive or DM medications with subsequent acute changes in their blood pressure or glucose level altering their diastolic function [52]. We acknowledge the possibility of these factors affecting the prevalence of DD among the enrolled subjects. Nevertheless, these selection biases do not explain the observed correlation between DD, elevated LVEDP and hs-CRP in asymptomatic patients. Furthermore, the biological plausibility reasoning we outlined in our discussion justifies further examination of our findings.

This was a cross sectional study with a single measurement of hs-CRP levels. Hence this study did not capture inherent variability of hs-CRP levels introduced by moderate alcohol consumption, increased activity and exercise, medications and other unknown variables or linear trends in hsCRP levels [53]. This limitation may explain the presence of DD in those with low hs-CRP levels. Alternatively there may be other markers of inflammation (e.g. IL-6) or collagen metabolism that could be more closely associated with DD. This study did not measure any other inflammatory markers or markers of collagen metabolism. It is likely that there are also non-inflammatory factors associated with DD. A prospective longitudinal study with serial measurement of hsCRP levels and other markers of inflammation and collagen metabolism is needed to address these issues. Also the study population was not tested for underlying coronary artery disease, which could also have an inflammatory origin and present as diastolic dysfunction. It was not considered necessary to subject an asymptomatic population to further risky or invasive testing in the absence of specific therapy other than modifying risk factors. Besides the purpose of this study is to report the association between inflammation and diastolic dysfunction in this population and delineating the mechanism of association is beyond the scope of this study.

\section{CONCLUSION}

Our data establishes a strong and independent association between hs-CRP levels and the presence of DD in asymptomatic AAs, which supports the concept of systemic inflammation as an etiological factor in myocardial fibrosis and LV dysfunction. If confirmed by larger, longitudinal studies this association may have implications in identifying the population at risk for heart failure and for possible new targets for treatment of DD and prevention of symptomatic heart failure. Hs-CRP levels may also identify individuals with advanced DD.

\section{ACKNOWLEDGEMENTS}

1. Philip R. Liebson, MD; Professor of Medicine, Senior Attending Physician, Preventive Cardiology, Rush University, Chicago, IL 60612.

2. Ms. Jackie Polk, RN; John Stroger, Jr. Hospital of Cook County, Chicago, IL 60612.

3. Ms. Bessie Coleman, RN; John Stroger, Jr. Hospital of Cook County, Chicago, IL 60612.

\section{FUNDING}

This study was supported by an internal financial grant from the divisions of Cardiology and Endocrinology at the John Stroger hospital of Cook county, Chicago, IL, USA.

Reagents for measurement of BNP were provided by Bayer diagnostics, New York, USA. Reagents for measurement of hs-CRP were provided by DPC, Los Angeles, California.

\begin{tabular}{|c|c|c|}
\hline \multicolumn{3}{|c|}{ ABBREVIATIONS } \\
\hline DD & $=$ & Diastolic dysfunction \\
\hline DD1 & $=$ & DD w/normal LVEDP \\
\hline DD2 & $=$ & DD with high LVEDP \\
\hline AA & $=$ & African Americans \\
\hline hs-CRP & $=$ & High sensitivity C-reactive protein \\
\hline $\mathrm{DM}$ & $=$ & Diabetes \\
\hline HTN & $=$ & Hypertension \\
\hline $\mathrm{BNP}$ & $=$ & B-type natriuretic peptide \\
\hline LVEDP & $=$ & Left ventricular end diastolic pressure \\
\hline $\mathrm{HbA}_{1} \mathrm{c}$ & $=$ & Hemoglobin $\mathrm{A}_{1} \mathrm{C}$ \\
\hline BNP & $=$ & Brain natriuretic peptide \\
\hline IVST & $=$ & Interventricular septal thickness \\
\hline PWT & $=$ & Posterior wall thickness \\
\hline LVID & $=$ & Left ventricular internal diameter \\
\hline ASE & $=$ & American Society of Echocardiography \\
\hline LV & $=$ & Left ventricular \\
\hline LVMI & $=$ & Left Ventricular mass index \\
\hline DT & $=$ & Deceleration time \\
\hline MMP & $=$ & Matrix metalloproteinases \\
\hline TIMPs & $=$ & $\begin{array}{l}\text { Tissue inhibitors of matrix metalloprotein- } \\
\text { ases }\end{array}$ \\
\hline
\end{tabular}

\section{REFERENCES}

[1] Gaasch WH, Zile MR. Left ventricular diastolic dysfunction and diastolic heart failure. Annu Rev Med 2004; 55: 373-94.

[2] Zile MR, Brutsaert DL. New concepts in diastolic dysfunction and diastolic heart failure: Part I: diagnosis, prognosis, and measurements of diastolic function. Circulation 2002; 105: 1387-93.

[3] Redfield MM, Jacobsen SJ, Burnett JC, Jr Mahoney DW, Bailey KR, Rodeheffer RJ. Burden of systolic and diastolic ventricular dysfunction in the community: appreciating the scope of the heart failure epidemic. JAMA 2003; 289: 194-202.

[4] Zile MR, Baicu CF, Gaasch WH. Diastolic heart failure-abnormalities in active relaxation and passive stiffness of the left ventricle. N Engl J Med 2004; 350: 1953-9.

[5] Senni M, Tribouilloy CM, Rodeheffer RJ, et al. Congestive heart failure in the community: a study of all incident cases in Olmsted County, Minnesota, in 1991. Circulation 1998; 98: 2282-9.

[6] Vasan RS, Larson MG, Benjamin EJ, Evans JC, Reiss CK, Levy D. Congestive heart failure in subjects with normal versus reduced left ventricular ejection fraction: prevalence and mortality in a population-based cohort. J Am Coll Cardiol 1999; 33: 1948-55. 
[7] Zile MR, Brutsaert DL. New concepts in diastolic dysfunction and diastolic heart failure: Part II: causal mechanisms and treatment. Circulation 2002; 105: 1503-8.

[8] Lorell BH, Carabello BA. Left ventricular hypertrophy: pathogenesis, detection, and prognosis. Circulation 2000; 102: 470-9.

[9] van Hoeven KH, Factor SM. A comparison of the pathological spectrum of hypertensive, diabetic, and hypertensive-diabetic heart disease. Circulation 1990; 82: 848-55.

[10] Kuwahara F, Kai H, Tokuda K, et al. Hypertensive myocardial fibrosis and diastolic dysfunction: another model of inflammation? Hypertension 2004; 43: 739-45.

[11] Albert MA, Torres J, Glynn RJ, Ridker PM. Perspective on selected issues in cardiovascular disease research with a focus on black Americans. Circulation 2004; 110: e7-12.

[12] NHANES Physician Examination Procedures Manual. Original January 1999 (Revised August 2000) [updated Original January 1999 (Revised August 2000) Revised August 2000; cited Original January 1999 Original January 1999 (Revised August 2000)]; Available from: http: //www.cdc.gov/nchs/data/nhanes/pe.pdf

[13] Chobanian AV, Bakris GL, Black HR, et al. The Seventh Report of the Joint National Committee on Prevention, Detection, Evaluation, and Treatment of High Blood Pressure: the JNC 7 report. JAMA 2003; 289: 2560-72.

[14] Genuth S, Alberti KG, Bennett P, et al. Follow-up report on the diagnosis of diabetes mellitus. Diabetes Care 2003; 26: 3160-7.

[15] Bush B, Shaw S, Cleary P, Delbanco TL, Aronson MD. Screening for alcohol abuse using the CAGE questionnaire. Am J Med 1987; 82: 231-5.

[16] Hu P, Greendale GA, Palla SL, et al. The effects of hormone therapy on the markers of inflammation and endothelial function and plasma matrix metalloproteinase-9 level in postmenopausal women: The postmenopausal estrogen progestin intervention (PEPI) trial. Atherosclerosis 2006; 185(2): 347-52.

[17] Post MS, van der Mooren MJ, Stehouwer CD, et al. Effects of transdermal and oral oestrogen replacement therapy on $\mathrm{C}$-reactive protein levels in postmenopausal women: a randomised, placebocontrolled trial. Thromb Haemost 2002; 88: 605-10.

[18] Ridker PM, Hennekens CH, Rifai N, Buring JE, Manson JE. Hormone replacement therapy and increased plasma concentration of C-reactive protein. Circulation 1999; 100: 713-6.

[19] Zegura B, Keber I, Sebestjen M, Koenig W. Double blind, randomized study of estradiol replacement therapy on markers of inflammation, coagulation and fibrinolysis. Atherosclerosis 2003; 168: 123-9.

[20] Sahn DJ, DeMaria A, Kisslo J, Weyman A. Recommendations regarding quantitation in M-mode echocardiography: results of a survey of echocardiographic measurements. Circulation 1978; 58: 1072-83.

[21] Devereux RB, Alonso DR, Lutas EM, et al. Echocardiographic assessment of left ventricular hypertrophy: comparison to necropsy findings. Am J Cardiol 1986; 57: 450-8.

[22] de Simone G, Daniels SR, Devereux RB, et al. Left ventricular mass and body size in normotensive children and adults: assessment of allometric relations and impact of overweight. J Am Coll Cardiol 1992; 20: 1251-60.

[23] Rakowski H, Appleton C, Chan KL, et al. Canadian consensus recommendations for the measurement and reporting of diastolic dysfunction by echocardiography: from the Investigators of Consensus on Diastolic Dysfunction by Echocardiography. J Am Soc Echocardiogr 1996; 9: 736-60.

[24] Hurrell DG, Nishimura RA, Ilstrup DM, Appleton CP. Utility of preload alteration in assessment of left ventricular filling pressure by Doppler echocardiography: a simultaneous catheterization and Doppler echocardiographic study. J Am Coll Cardiol 1997; 30: 459-67.

[25] Dokainish H, Zoghbi WA, Lakkis NM, et al. Optimal noninvasive assessment of left ventricular filling pressures: a comparison of tissue Doppler echocardiography and B-type natriuretic peptide in patients with pulmonary artery catheters. Circulation 2004; 109: 2432-9.

[26] Nagueh SF, Middleton KJ, Kopelen HA, Zoghbi WA, Quinones MA. Doppler tissue imaging: a noninvasive technique for evaluation of left ventricular relaxation and estimation of filling pressures. J Am Coll Cardiol 1997; 30: 1527-33.

[27] Ommen SR, Nishimura RA, Appleton CP, et al. Clinical utility of Doppler echocardiography and tissue Doppler imaging in the es- timation of left ventricular filling pressures: A comparative simultaneous Doppler-catheterization study. Circulation 2000; 102: 1788-94.

[28] Nagueh SF, Appleton CP, Gillebert TC, et al. Recommendations for the evaluation of left ventricular diastolic function by echocardiography. J Am Soc Echocardiogr 2009; 22: 107-33.

[29] Nicoletti A, Michel JB. Cardiac fibrosis and inflammation: interaction with hemodynamic and hormonal factors. Cardiovasc Res 1999; 41: 532-43.

[30] Siwik DA, Colucci WS. Regulation of matrix metalloproteinases by cytokines and reactive oxygen/nitrogen species in the myocardium. Heart Fail Rev 2004; 9: 43-51.

[31] Yambe M, Tomiyama H, Hirayama Y, et al. Arterial stiffening as a possible risk factor for both atherosclerosis and diastolic heart failure. Hypertens Res 2004; 27: 625-31.

[32] Kawaguchi M, Hay I, Fetics B, Kass DA. Combined ventricular systolic and arterial stiffening in patients with heart failure and preserved ejection fraction: implications for systolic and diastolic reserve limitations. Circulation 2003; 107: 714-20.

[33] Pirro M, Schillaci G, Savarese G, et al. Low-grade systemic inflammation impairs arterial stiffness in newly diagnosed hypercholesterolaemia. Eur J Clin Invest 2004; 34: 335-41.

[34] Kass DA. Ventricular arterial stiffening: integrating the pathophysiology. Hypertension 2005; 46: 185-93.

[35] Din-Dzietham R, Couper D, Evans G, Arnett DK, Jones DW. Arterial stiffness is greater in African Americans than in whites: evidence from the Forsyth County, North Carolina, ARIC cohort. Am J Hypertens 2004; 17: 304-13.

[36] Aurigemma GP, Gottdiener JS, Shemanski L, Gardin J, Kitzman D. Predictive value of systolic and diastolic function for incident congestive heart failure in the elderly: the cardiovascular health study. J Am Coll Cardiol 2001; 37: 1042-8.

[37] Shah SJ, Marcus GM, Gerber IL, et al. High-sensitivity C-reactive protein and parameters of left ventricular dysfunction. J Card Fail 2006; 12: 61-5.

[38] Dahlstrom U. Can natriuretic peptides be used for the diagnosis of diastolic heart failure? Eur J Heart Fail 2004; 6: 281-7.

[39] Bibbins-Domingo K, Ansari M, Schiller NB, Massie B, Whooley MA. Is B-type natriuretic peptide a useful screening test for systolic or diastolic dysfunction in patients with coronary disease? Data from the Heart and Soul Study. Am J Med 2004; 116: 509-16.

[40] Janicki JS, Brower GL, Henegar JR, Wang L. Ventricular remodeling in heart failure: the role of myocardial collagen. Adv Exp Med Biol 1995; 382: 239-45.

[41] Li YY, McTiernan CF, Feldman AM. Interplay of matrix metalloproteinases, tissue inhibitors of metalloproteinases and their regulators in cardiac matrix remodeling. Cardiovasc Res 2000; 46: 214-24.

[42] Weber KT. Extracellular matrix remodeling in heart failure: a role for de novo angiotensin II generation. Circulation 1997; 96: 4065-82.

[43] Lin R, Liu J, Gan W, Yang G. C-reactive protein-induced expression of CD40-CD40L and the effect of lovastatin and fenofibrate on it in human vascular endothelial cells. Biol Pharm Bull 2004; 27: 1537-43.

[44] Lee SW, Song KE, Shin DS, et al. Alterations in peripheral blood levels of TIMP-1, MMP-2, and MMP-9 in patients with type-2 diabetes. Diabetes Res Clin Pract 2005; 69: 175-9.

[45] Ogata T, Miyauchi T, Sakai S, Takanashi M, Irukayama-Tomobe Y, Yamaguchi I. Myocardial fibrosis and diastolic dysfunction in deoxycorticosterone acetate-salt hypertensive rats is ameliorated by the peroxisome proliferator-activated receptor-alpha activator fenofibrate, partly by suppressing inflammatory responses associated with the nuclear factor-kappa-B pathway. J Am Coll Cardiol 2004; 43: 1481-8.

[46] Kuwahara F, Kai H, Tokuda K, et al. Transforming growth factor-beta function blocking prevents myocardial fibrosis and diastolic dysfunction in pressure-overloaded rats. Circulation 2002; 106: $130-5$

[47] Varagic J, Frohlich ED, Diez J, et al. Myocardial fibrosis, impaired coronary hemodynamics, and biventricular dysfunction in saltloaded SHR. Am J Physiol Heart Circ Physiol 2006; 290: H1503-9.

[48] Brilla CG, Janicki JS, Weber KT. Impaired diastolic function and coronary reserve in genetic hypertension. Role of interstitial fibrosis and medial thickening of intramyocardial coronary arteries. Circ Res 1991; 69: 107-15. 
[49] Erdogan D, Yildirim I, Ciftci O, et al. Effects of normal blood pressure, prehypertension, and hypertension on coronary microvascular function. Circulation 2007; 115: 593-9.

[50] Yusuf S, Pfeffer MA, Swedberg K, et al. Effects of candesartan in patients with chronic heart failure and preserved left-ventricular ejection fraction: the CHARM-Preserved Trial. Lancet 2003; 362: $777-81$.

[51] Givertz MM, Colucci WS. New targets for heart-failure therapy: endothelin, inflammatory cytokines, and oxidative stress. Lancet 1998; 352(Suppl 1): SI34-8.
[52] Kazlauskaite R, Doukky R, Evans A, et al. Predictors of diastolic dysfunction among minority patients with newly diagnosed type 2 diabetes. Diabetes Res Clin Pract 2010; 88(2): 189-95.

[53] Pearson TA, Mensah GA, Alexander RW, et al. Markers of inflammation and cardiovascular disease: application to clinical and public health practice: A statement for healthcare professionals from the Centers for Disease Control and Prevention and the American Heart Association. Circulation 2003; 107: 499-511.

Received: June 08, 2011

Revised: June 27, 2011

Accepted: June 30, 2011

(C) Rajaram et al.; Licensee Bentham Open.

This is an open access article licensed under the terms of the Creative Commons Attribution Non-Commercial License (http://creativecommons.org/licenses/ by-nc/3.0/) which permits unrestricted, non-commercial use, distribution and reproduction in any medium, provided the work is properly cited. 